\title{
Elucidating reactivity regimes in cyclopentane oxidation: jet stirred reactor experiments, computational chemistry, and kinetic modeling
}

Mariam J. Al Rashidi ${ }^{a}$, Sébastien Thion ${ }^{b}$, Casimir Togbé ${ }^{b}$, Guillaume Dayma $^{b}$, Marco Mehl $^{c}$, Philippe Dagaut ${ }^{b}$, William J. Pitz ${ }^{c}$, Judit Zádor ${ }^{d}$ and S. Mani Sarathy ${ }^{a}$

${ }^{a}$ King Abdullah University of Science and Technology (KAUST), Clean Combustion Research Center (CCRC), Thuwal 23955-6900, Saudi Arabia

${ }^{\mathrm{b}}$ C.N.R.S.-I.N.S.I.S., Institut de Combustion, Aérothermique, Réactivité et Environnement, 1C, Avenue de la Recherche Scientifique, 45071 Orléans Cedex 2, France

${ }^{\mathrm{c}}$ Lawrence Livermore National Laboratory, Livermore, California, USA

${ }^{\mathrm{d}}$ Combustion Research Facility, Sandia National Laboratories, MS 9055, Livermore, CA 94551 USA

*Corresponding author:

Dr. Mariam Al Rashidi

Clean Combustion Research Center

King Abdullah University of Science and Technology

Al Kindi bldg. level 4, room 4326-WS11

Thuwal, 23955-6900, Jeddah, Saudi Arabia

Tel: 966544700179 E-mail: mariam.elrachidi@kaust.edu.sa

Colloquium: Reaction kinetics

Total length of paper (method 1): 5948 words

Main text: $\quad 3299$ words

References: 595 words

Tables: 118 words

Figures: 1936 words 


\section{Abstract}

This study is concerned with the identification and quantification of species generated during the combustion of cyclopentane in a jet stirred reactor (JSR). Experiments were carried out for temperatures between 740 and $1250 \mathrm{~K}$, equivalence ratios from 0.5 to 3.0, and at an operating pressure of 10 atm. The fuel concentration was kept at $0.1 \%$ and the residence time of the fuel $/ \mathrm{O}_{2} / \mathrm{N}_{2}$ mixture was maintained at $0.7 \mathrm{~s}$. The reactant, product, and intermediate species concentration profiles were measured using gas chromatography and Fourier transform infrared spectroscopy. The concentration profiles of cyclopentane indicate inhibition of reactivity between $850-1000 \mathrm{~K}$ for $\varphi=2.0$ and $\varphi=3.0$. This behavior is interesting, as it has not been observed previously for other fuel molecules, cyclic or non-cyclic. A kinetic model including both low- and high-temperature reaction pathways was developed and used to simulate the JSR experiments. The pressure-dependent rate coefficients of all relevant reactions lying on the PES of cyclopentyl $+\mathrm{O}_{2}$, as well as the $\mathrm{C}-\mathrm{C}$ and $\mathrm{C}-\mathrm{H}$ scission reactions of the cyclopentyl radical were calculated at the UCCSD(T)-F12b/cc-pVTZ-F12//M06-2X/6-311++G(d,p) level of theory. The simulations reproduced the unique reactivity trend of cyclopentane and the measured concentration profiles of intermediate and product species. Sensitivity and reaction path analyses indicate that this reactivity trend may be attributed to differences in the reactivity of allyl radical at different conditions, and it is highly sensitive to the $\mathrm{C}-\mathrm{C} / \mathrm{C}-\mathrm{H}$ scission branching ratio of the cyclopentyl radical decomposition.

\section{Keywords}

Cyclopentane, jet-stirred rector, species profiles, modeling 


\section{Introduction}

Cycloalkanes are significant constituents of fuels, particularly those derived from oil sands and shale. They have greater propensity for soot formation than their non-cyclic counterparts due to dehydrogenation reactions [1]. Cycloalkanes and $n$-alkanes have similar chemistry except for some reactions whose rate coefficients are affected by the ring structure [2]. Studies have shown that cycloalkanes are less reactive, as evidenced by their longer ignition delay times [3] and higher octane numbers [4]. Moreover, methyl substitution, which is known to reduce reactivity of normal alkanes, has the opposite effect on cycloalkanes [5] since the addition of a methyl group promotes alkylperoxy isomerizations resulting in low-temperature chain branching [6]. Data currently available is not enough to explain the differences in ignition properties and reactivity trends of these compounds. This emphasizes the need for comprehensive and well validated cycloalkane kinetic models.

Among the different cycloalkane species, cyclopentane and cyclohexane are of particular importance because they are often used to represent naphthenes in surrogate fuels. These components, especially cyclopentane, significantly influence the fuel combustion and ignition characteristics of a gasoline surrogate, as demonstrated recently by [7]. However, most of the cycloalkane combustion research has been focused on cyclohexane [8-10]. Only a few studies provide kinetic models for cyclopentane combustion. These include high-temperature oxidation mechanisms developed by Tian et al. [5] based on the JetSurF2.0 mechanism and by Sirjean et al. [11] using EXGAS software. These mechanisms have been validated against shocktube ignition data measured under relatively dilute conditions $(0.5$ and $1 \%$ fuel/oxidant mixtures) in Argon for the temperature range of 1100-1800 K, at pressures up to 8.4 atm, and equivalence ratios between 0.5 and 2.0 [5, 11]. Daley et al. [12] provided high-temperature ignition data for cyclopentane and cyclohexane fuel/air mixtures at lean/stoichiometric conditions and relatively high pressures (13 and $45 \mathrm{~atm})$. One experimental study measured the flame speeds of cyclopentane 
using the counterflow configuration at atmospheric pressure [13]. Finally, Simon et al. [14] measured species profiles of cyclopentane $/ \mathrm{O}_{2}$ mixtures in a jet stirred reactor at $873 \mathrm{~K}$ and $0.5 \mathrm{~atm}$.

Here we develop a detailed kinetic model comprising low- and high- temperature reaction pathways capable of predicting the combustion characteristics of cyclopentane. We also calculated pressuredependent rate coefficients for the cyclopentyl $+\mathrm{O}_{2}$ reaction for which no good estimates were available. Computations of the $\mathrm{C}-\mathrm{C}$ and $\mathrm{C}-\mathrm{H}$ cyclopentyl scission kinetics were also conducted to reconcile discrepancies in the literature. The mechanism is validated against species profiles measured in a jet stirred reactor. A unique reactivity trend is observed for experimental and simulated profiles at rich conditions. To the best of our knowledge, this study is the first to fully develop a detailed mechanism of cyclopentane combustion and to provide experimental concentration profiles.

\section{Experimental}

The experimental setup used has been described previously [15]. Briefly, it consists of a fused silica jet stirred reactor (JSR) placed inside an electrical resistance oven which in turn is placed inside a pressure resistant jacket. $98 \%$ pure liquid cyclopentane (2\% n-pentane), supplied by Aldrich, was pumped, vaporized and atomized at $100{ }^{\circ} \mathrm{C}$ using an HPLC pump and a flow of nitrogen. The preheated flow of fuel/ $\mathrm{N}_{2}$ was blended with a flow of oxygen diluted in nitrogen at the entrance of the injectors. Flow rates of all gases were controlled using mass-flow controllers, and the temperature measured by a $\mathrm{Pt} / \mathrm{Pt}-\mathrm{Rh} 10 \%$ thermocouple placed along the vertical axis of the reactor to check thermal uniformity. Experiments were performed at temperatures between 740 and $1250 \mathrm{~K}$ at a pressure of $10 \mathrm{~atm}$. The fuel concentration was kept at $0.1 \%$; however, the concentration of $\mathrm{O}_{2}$ was varied from one experiment to the other such that the equivalence ratios were $0.5,1.0,1.5,2.0$ and 3.0. The measurements were conducted under steady state conditions at a constant mean residence time of $0.7 \mathrm{~s}$. 
The reaction mixtures were collected at low pressures in $1 \mathrm{~L}$ Pyrex bulbs using a sonic sampling probe. The collected samples were analyzed by a gas chromatograph (GC). Flame ionization detection was used to identify and quantify hydrocarbon and oxygenated species whereas thermal conductivity detection was used for the analysis of $\mathrm{H}_{2}$ and $\mathrm{O}_{2}$. In addition to $\mathrm{GC}$, we used on-line Fourier transform infra-red spectroscopy (FTIR) for the analysis of the reaction mixture. This was achieved by introducing the collected samples into a thermostatic gas cell, $10 \mathrm{~m}$ optical length, at $140{ }^{\circ} \mathrm{C}$ via a heated Teflon line and under vacuum. When the sample pressure reached 0.2 atm inside the cell, FTIR spectra were acquired at a resolution of $0.5 \mathrm{~cm}^{-1}$. Mole fraction profiles acquired using FTIR analysis are in agreement with those determined using GC (uncertainty within 10\%).

\section{Kinetic modeling}

A comprehensive mechanism of cyclopentane oxidation was developed using the recently published AramcoMech 1.4 as base chemistry [16]. The kinetic model is presented in further detail in Ref. [17]. Briefly, it consists of high- and low-temperature oxidation reactions whose rate coefficients were taken from the literature, if available. Otherwise, we made use of rate rules and analogies, except for the low-

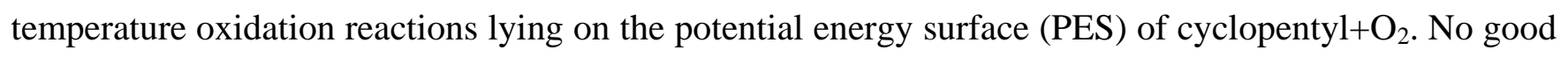
analogies could be found for these reactions, especially considering the findings of Yang and coworkers $[2,18]$, which showed that low-temperature cycloalkane oxidation chemistry is decidedly different from that of $n$-alkanes due to the conformational inhibition of several $\mathrm{RO}_{2} / \mathrm{QOOH}$ isomerization chain branching pathways. Considering that the conformation of a cyclic species depends on the ring size, analogies with cyclohexane are also inappropriate. Furthermore, it has been shown that formally direct (well-skipping) pathways of cyclic $\mathrm{RO}_{2}$ species contribute to the formation of $\mathrm{OH}$ on short timescales even at high pressures, and thus may affect autoignition [8]. We conducted a separate study [17] wherein we computationally investigated the PES of cyclopentyl $+\mathrm{O}_{2}$ at the UCCSD(T)-F12b/cc-pVTZF12//M06-2X/6-311++G(d,p) level of theory using Gaussian 09 [19] and MOLPRO [20]. Pressure- 
dependence of these reactions was calculated by solving the 1-D time-dependent multiwell master equation using the PAPER code [21]. Further details regarding the computational aspects of the study may be found in [17].

The C-C and $\mathrm{C}-\mathrm{H} \beta$-scissions of the cyclopentyl radical are crucial, yet the rate coefficients reported in the literature have significant differences. Tsang [22] estimated the rate coefficients of cyclopentyl scission based on experimental data reported for similar compounds, Sirjean et al. [11] and Wang et al. [23] determined these parameters based on CBS-QB3 and CBS-QB3/QRRK/MSC calculations, respectively, while Awan et al. [24] used a combination of shocktube measurements and RRKM/ME calculations. The high pressure limit rate constants from these references are different by up to a factor of 16 (Figs. S1 and S2) due to differences in both activation barriers and frequency factors (Table S1). Since none of the reported values were suitable for reproducing the experimental concentration profiles at all conditions, we recalculated the high-pressure limit rate coefficients of the cyclopentyl radical scission reactions. We used Gaussian 09 for geometry optimization and frequency calculation of stable species and transition states at the M06-2X/6-311++G(d,p) level of theory; while single point energy calculations of the optimized structures were conducted at the UCCSD(T)-F12b/cc-pVTZ-F12 level of theory using MOLPRO. Pressure-dependence was determined based on the falloff parameters reported by Wang et al. [23]. These calculated values are used in the final version of the mechanism since they were shown to give the best agreement with experiments (Section 4.2).

Thermodynamic properties of new chemical species were calculated via two methods: computational chemistry and group additivity. Quantum mechanical calculations were used for thermodynamic properties of species involved in the $\mathrm{R}+\mathrm{O}_{2}$ and $\beta$-scission reactions subjected to computational methods. For all remaining species, the THERM software [25] with Benson's group additivity methods [26] was utilized. The mechanism was validated against the experimental JSR data using the transient perfectly- 
stirred reactor model of the CHEMKIN PRO software package [27] with an end time of $50 \mathrm{~s}$, which was sufficient to reach steady state conditions.

\section{Results and discussion}

\subsection{Experimental and simulated concentration profiles}

The experimental fuel concentration profiles at $\varphi=0.5,1.0,1.5,2.0$ and 3.0 as a function of temperature are presented in Fig. 1. The figure shows that fuel reactivity is the same for all conditions up to $800 \mathrm{~K}$ indicating no low temperature reactivity at the given conditions. At $830 \mathrm{~K}$, reactivity decreases with increasing equivalence ratio up to $1160 \mathrm{~K}$. At higher temperatures, the system is reactive for all conditions. The general trend is that reactivity increases with increasing temperature, but this does not apply at rich conditions where we observe inhibition of reactivity from 950 to $980 \mathrm{~K}$ and from 860 to $980 \mathrm{~K}$ for $\varphi=2.0$ and 3.0, respectively. This behavior cannot be attributed to the transition from low to high temperature chemistry (NTC behavior) for two reasons. First, the behavior becomes more prominent at richer instead of leaner conditions. The opposite is expected for low temperature NTC behavior for mixtures with a constant fuel concentration: the oxygen mole fraction must be lowered to attain richer mixtures which reduces the importance of $\mathrm{R}+\mathrm{O}_{2}$ reactions and low temperature chemistry. Second, the behavior occurs at relatively high temperatures where alkylperoxy radicals $\left(\mathrm{RO}_{2}\right)$ are less stable. Such profiles are unique, and, to the best of our knowledge, have not been observed for other species, including cyclohexane [28]. As discussed later on in this section, this behavior depends to a great extent on the $\mathrm{C}-\mathrm{C} / \mathrm{C}-\mathrm{H}$ branching ratio of cyclopentyl scission as well as the reactivity of the allyl radical. 


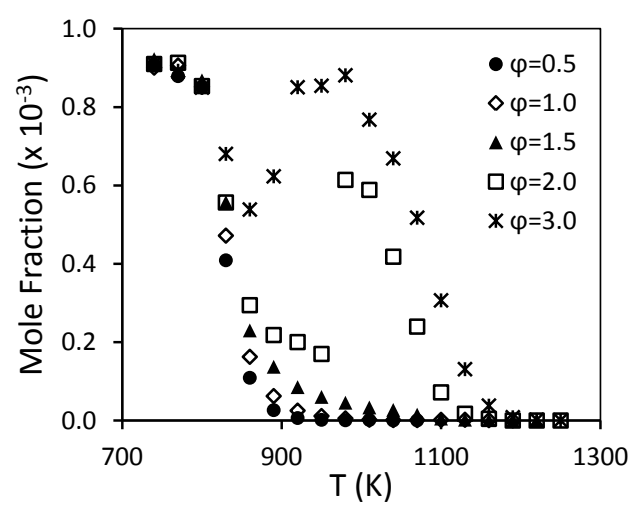

Fig. 1. Experimental concentration profiles of cyclopentane with increasing JSR temperature and for different equivalence ratios ( $\mathrm{P}=10 \mathrm{~atm}, 0.1 \%$ fuel $/ \mathrm{O}_{2} / \mathrm{N}_{2}$ mixtures).

Figs. 2, 3, and 4 depict the experimental and simulated concentration profiles of the major identified species for lean, stoichiometric, and rich conditions, respectively. The model reproduces the profiles of reactants $\left(\mathrm{CPT}\right.$ and $\left.\mathrm{O}_{2}\right)$ and products $\left(\mathrm{CO}_{2}\right.$ and $\left.\mathrm{H}_{2} \mathrm{O}\right)$ at $\varphi=0.5$ and $\varphi=1.0$. However, although the model predicts the inhibition of reactivity at $\varphi=3.0$, it is less reactive between 850 and $880 \mathrm{~K}$, and more reactive between 1000 and $1130 \mathrm{~K}$. The major species identified are cyclopentane (CPT), O2, H2, CO, $\mathrm{CO} 2, \mathrm{H} 2 \mathrm{O}$, cyclopentene (CYC5H8), cyclopentadiene (CYC5H6), propene (C3H6), ethane (C2H6), ethene $(\mathrm{C} 2 \mathrm{H} 4)$, acetylene $(\mathrm{C} 2 \mathrm{H} 2)$, methane $(\mathrm{CH} 4)$, benzene $(\mathrm{C} 6 \mathrm{H} 6)$, formaldehyde $(\mathrm{CH} 2 \mathrm{O})$, acetaldehyde $(\mathrm{CH} 3 \mathrm{CHO})$, and propenal $(\mathrm{C} 2 \mathrm{H} 3 \mathrm{CHO})$. The profiles of $\mathrm{CH} 2 \mathrm{O}, \mathrm{CH} 3 \mathrm{CHO}, \mathrm{C} 2 \mathrm{H} 3 \mathrm{CHO}$, C2H6 and C6H6 are presented in Figs. S3-7. The identified hydrocarbon species are the same as those detected by Simon et al. [14]. The model captures the profiles of these species well from a qualitative perspective. Quantitatively, cyclopentene and cyclopentadiene concentrations are accurately predicted (less than $10 \%$ difference in maximum concentrations compared with the experimental values). The concentration profiles of $\mathrm{CO}, \mathrm{CO} 2, \mathrm{H} 2 \mathrm{O}$ and $\mathrm{H} 2$ are relatively well predicted with maximum deviations from experimental values of $40-50 \%$. The model under-predicts the concentrations of unsaturated hydrocarbons $\left(1-\mathrm{C}_{4} \mathrm{H}_{8}, \mathrm{C}_{4} \mathrm{H}_{6}, \mathrm{C}_{3} \mathrm{H}_{6}\right.$, and $\left.\mathrm{C}_{2} \mathrm{H}_{4}\right)$ by up $50 \%$, and those of oxygenated $\left(\mathrm{CH}_{2} \mathrm{OO}, \mathrm{CH}_{3} \mathrm{CHO}\right.$, and $\mathrm{C}_{2} \mathrm{H}_{3} \mathrm{CHO}$ ) intermediates and benzene whose profiles are depicted in Figs. S3-7, by up to 70\%. The 
greatest discrepancies between the model and experimental data are observed for $\mathrm{C} 2 \mathrm{H} 2$, where the peak concentrations vary by almost $90 \%$ at lean and stoichiometric conditions. At these conditions, the model over-predicts $\mathrm{C} 2 \mathrm{H} 2$ concentrations. Experiments were also conducted at $\varphi=1.5$ and $\varphi=2.0$ (Figs. S8 and S9). The same intermediate species were identified at these conditions, albeit at different concentrations. Inhibition of reactivity is observed at $\varphi=2.0$, but not at $\varphi=1.5$. For $\varphi=3.0$, this unique behavior is of greater magnitude, i.e., it is observed for a wider temperature range (850-1000 K), than for $\varphi=2.0$.
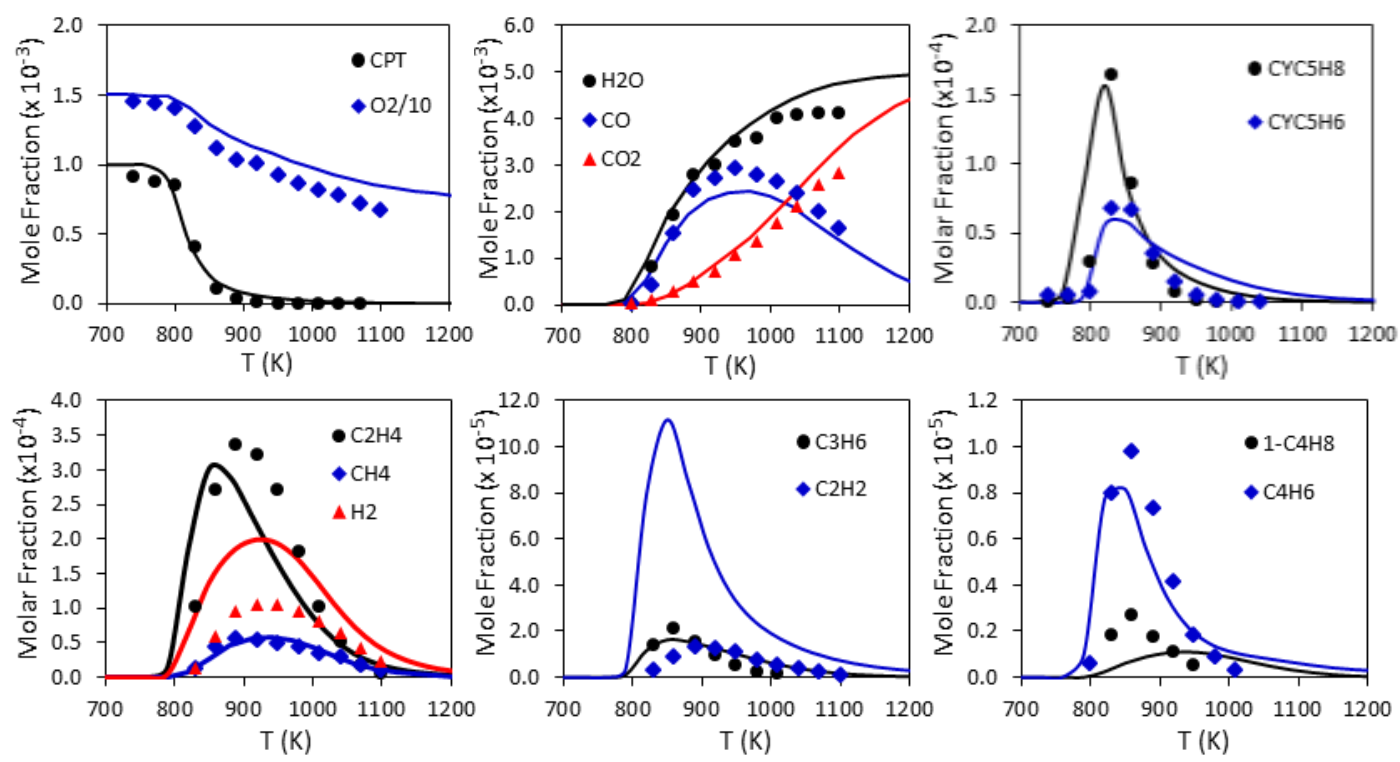

Fig. 2. Experimental (symbols) and modeled (lines) concentration profiles of detected species at $\mathrm{P}=10$ atm and $\varphi=0.5$ 

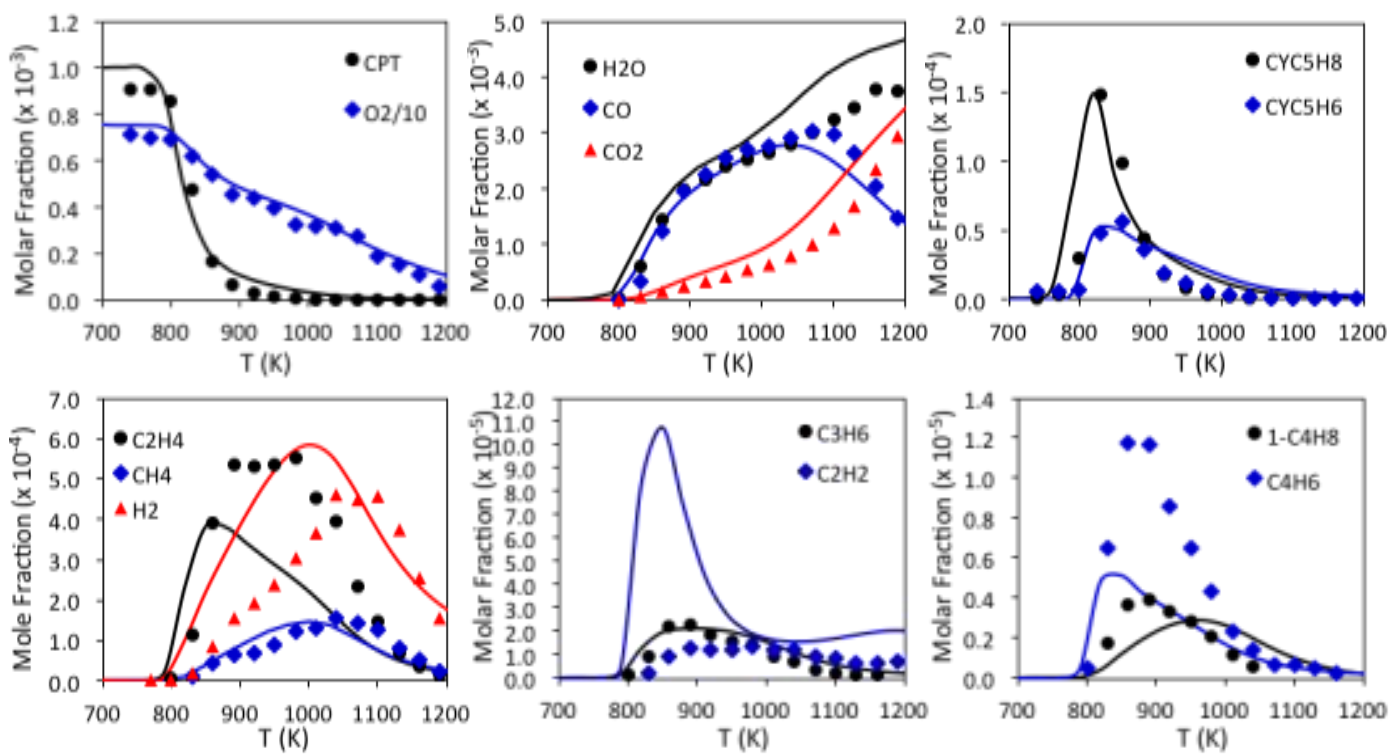

Fig. 3. Experimental (symbols) and modeled (lines) concentration profiles of detected species at $\mathrm{P}=10$ atm and $\varphi=1.0$
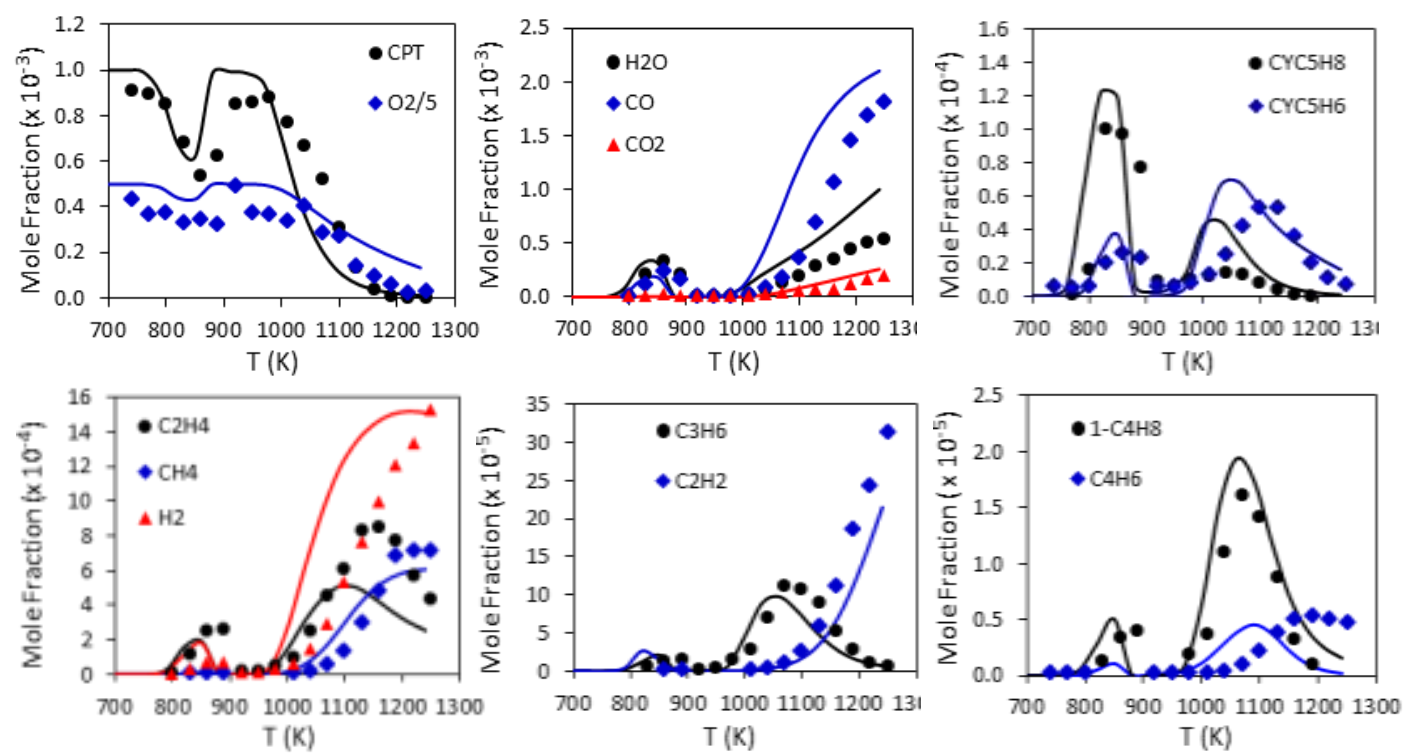

Fig. 4. Experimental (symbols) and modeled (lines) concentration profiles of detected species at $\mathrm{P}=10$ atm and $\varphi=3.0$

\subsection{Effect of $C$ - $C$ and $C$ - $H$ $\beta$-scission reactions}


Table 1 and Fig. S10 show that the $\mathrm{C}-\mathrm{C} / \mathrm{C}-\mathrm{H}$ branching ratios calculated in this study and those reported in the literature exhibit significant variations in magnitude and temperature dependence. Branching ratios from [24] and [22] show no temperature dependence; whereas the ratios from [11], [23], and this study decrease with increasing temperature. At temperatures greater than $700 \mathrm{~K}$, the branching ratios determined herein are higher than those reported by [11] and [23]. These differences have an immense effect on simulations of jet stirred reactor oxidation, particularly at rich conditions.

Table 1. C-C/C-H scission branching ratios of the cyclopentyl radical at 500, 1000 and $1500 \mathrm{~K}$ based on literature high pressure limit rate coefficients and this study

\begin{tabular}{|c|c|c|c|c|c|c|}
\hline & & Tsang [22] & Awan [24] & Sirjean [11] & Wang [23] & This study \\
\hline \multirow{3}{*}{ 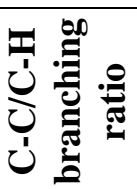 } & $500 \mathrm{~K}$ & 0.7 & 3.22 & 0.97 & 2.63 & 1.53 \\
\hline & $1000 \mathrm{~K}$ & 0.86 & 3.49 & 0.37 & 0.55 & 0.84 \\
\hline & $1500 \mathrm{~K}$ & 0.87 & 3.33 & 0.26 & 0.39 & 0.63 \\
\hline
\end{tabular}

Fig. 5 presents concentration profiles of cyclopentane using different coefficients for scission reactions at $\varphi=3.0$. The use of scission coefficients from [24] results in no reactivity at temperatures lower than $970 \mathrm{~K}$ for all investigated equivalence ratios. [23] shows no reactivity up to $940 \mathrm{~K}$, and [22] exhibits significant inhibition of reactivity between 820 and $950 \mathrm{~K}$. However, at $\varphi=2.0$ (Fig. S11) we observe high reactivity using coefficients from [22] and inhibition of reactivity from 800 to $900 \mathrm{~K}$ using those from [23]. Coefficients from [11] and this study show inhibition of reactivity at $\varphi=3.0$. Better fits to experimental data are obtained when using the scission rate coefficients determined here, as shown in Fig. 5. At $\varphi=2.0$, Sirjean et al.'s coefficients [11] and those determined herein yield high reactivity with no inhibition, unlike the experimental profile. Inhibition of reactivity starts to show at $\varphi=2.85$ and $\varphi=2.20$ when using rate parameters from [11] and this study, respectively (Figs. S12 and S13). The reactivity trends are thus affected by the absolute and relative rates of $\mathrm{C}-\mathrm{C}$ and $\mathrm{C}-\mathrm{H}$ scission reaction of the cyclopentyl radical. Considering the uncertainties involved in experimental measurements, we 
conclude that the mechanism proposed in this work is only capable of qualitatively reproducing the experimental profiles of cyclopentane at all conditions if the $\mathrm{C}-\mathrm{C}$ and $\mathrm{C}-\mathrm{H}$ cyclopentyl scission rate coefficients calculated herein are used.

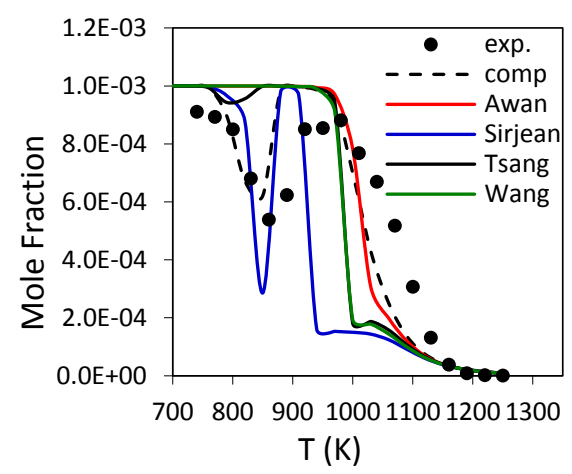

Fig. 5. Experimental and simulated concentration profiles of cyclopentane at $P=10$ atm and $\varphi=3.0$ using rate coefficients for C-C and C-H scission of cyclopentyl from different references [11, 22-24]. "Comp" refers to the use of rate parameters determined computationally in this study for $\mathrm{C}-\mathrm{C}$ and $\mathrm{C}-\mathrm{H}$ scission.

\subsection{Reaction path and sensitivity analyses}

In order to understand the reason for the unique reactivity trend of cyclopentane, reaction path analyses were conducted at $\varphi=3.0$ where inhibition was observed, including $850 \mathrm{~K}$ where inhibition starts and $880 \mathrm{~K}$ which is a temperature at maximum inhibition. Also investigated is $\varphi=1.0$ where no inhibition was observed using the same temperature of $880 \mathrm{~K}$. The main pathways are depicted in Fig. 6 along with the relative contributions of every pathway to the total reaction rate. Cyclopentane is consumed via $\mathrm{H}$-abstraction reactions to produce the cyclopentyl radical (CYC5H9). The important abstracting species (R) are $\mathrm{OH}$ and $\mathrm{H}$ radicals that are responsible for $83-90 \%$ of total fuel consumption. The fuel radical mainly undergoes $\mathrm{C}-\mathrm{C}$ and $\mathrm{C}-\mathrm{H}$ scission reactions (> 70\%) to produce 1-pentenyl radical $(\mathrm{C} 5 \mathrm{H} 91-5)$ and cyclopentene $+\mathrm{H}$, respectively. The cyclopentyl radical also undergoes $\mathrm{O}_{2^{-}}$ addition to give the peroxy radical CPTO2J (9-17\%), as well as cyclopentene CYC5H8 (5-9\%), alkoxy 
radical CPTOJ (0-1\%), and cyclic ether CPTYO12 (0-1\%) (refer to Fig. 6 for the chemical structures of these species). The latter species are formed via formally direct pathways.

At $\varphi=3$ and $\mathrm{T}=880 \mathrm{~K}$, conditions where cyclopentane exhibits inhibition of reactivity, its conjugate olefin (i.e., cyclopentene) mainly undergoes unimolecular decomposition (77\%) compared to $\mathrm{H}-$ abstraction (11\%). However, at $\varphi=3 / \mathrm{T}=850 \mathrm{~K}$ and $\varphi=1 / \mathrm{T}=880 \mathrm{~K}, \mathrm{H}$-abstraction pathways are more dominant (> 90\%). The rate coefficients of the unimolecular decomposition and abstraction reactions of cyclopentene are taken from [29] and [30], respectively. The product of unimolecular decomposition undergoes addition and abstraction reactions, which lead to the formation of unsaturated hydrocarbons (butene, butadiene, propene, and acetylene) and aldehydes (formaldehyde, acetaldehyde, and propenal). The H-abstraction products, on the other hand, are converted to cyclopentadiene. The cyclopentenyl radical CYC5H71-3 also produces resonantly stabilized radicals $\mathrm{C} * \mathrm{CC} * \mathrm{CCJ}$ and CPT1ENOJ. Although major differences in cyclopentene chemistry are observed at conditions with and without inhibition of reactivity, sensitivity analyses carried out at these conditions (see discussion below) show that fuel reactivity is not highly sensitive to any of the decomposition or oxidation reactions of cyclopentene.

1-pentenyl dissociates almost completely to ethene and allyl radical regardless of temperature and equivalence ratio. At $\varphi=3 / 850 \mathrm{~K}$ and $\varphi=1 / 880 \mathrm{~K}$, the allyl radical reacts with $\mathrm{HO}_{2}$ and leads to $\mathrm{C} 3 \mathrm{H} 5 \mathrm{O}+\mathrm{OH}(54-64 \%)$. This pathway promotes reactivity since it produces reactive $\mathrm{OH}$ radicals from non-reactive radicals $\left(\mathrm{C} 3 \mathrm{H} 5-\mathrm{A}\right.$ and $\left.\mathrm{HO}_{2}\right)$. Meanwhile, at $\varphi=3 / 880 \mathrm{~K}$ the $\mathrm{HO}_{2}$ radical concentration is greatly reduced (see Fig. S14) and the dominant pathway (61\%) is recombination of two allyl radicals to form stable species $(\mathrm{C} 6 \mathrm{H} 10)$ that leads to chain termination. The rate coefficients of allyl recombination are taken from Lynch et al. [31] and those of reaction with $\mathrm{HO}_{2}$ from Goldsmith et al. [32]. 


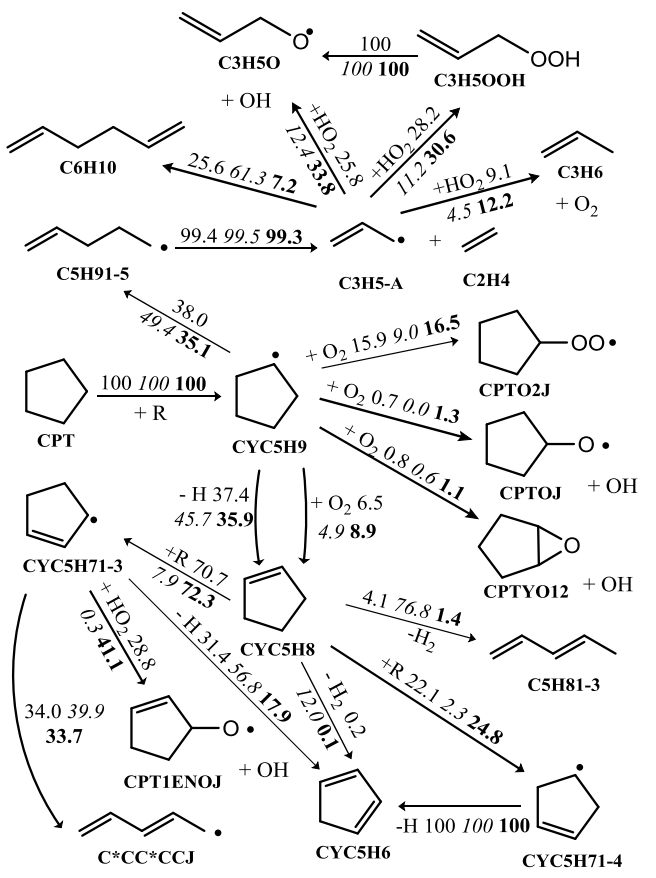

Fig. 6. Reaction path analysis of cyclopentane decomposition for $\varphi=3 / 850 \mathrm{~K}$ (plain font), $\varphi=3 / 880 \mathrm{~K}$ (italic font), and $\varphi=1 / 880 \mathrm{~K}$ (bold font)

Sensitivity analyses on fuel concentration were conducted at $\varphi=3 / 850 \mathrm{~K}$ (start of inhibition) and $\varphi=3 / 880 \mathrm{~K}$ (maximum inhibition). First-order sensitivity coefficients with the highest absolute values are presented in Fig. 7. Positive sensitivity coefficients indicate that increasing reaction rate increases fuel concentration (decreases reactivity) and vice versa. The $880 \mathrm{~K}$ sensitivities are multiplied by 10 for easy examination because the $850 \mathrm{~K}$ case is more sensitive to changes in rate constants. The $880 \mathrm{~K}$ case also shows sensitivities to a smaller number of reactions than at $850 \mathrm{~K}$. C-C and C-H scission reactions of the cyclopentyl radical are important at both conditions. The $\mathrm{C}-\mathrm{H}$ scission pathway increases reactivity, whereas the $\mathrm{C}-\mathrm{C}$ scission pathway leading to formation of stable ethene and allyl radicals suppresses reactivity. $\mathrm{H}$-abstraction reactions are also important. $\mathrm{H}$-abstraction by $\mathrm{HO}_{2}$ radicals promotes reactivity, whereas $\mathrm{H}$-abstraction by $\mathrm{H}$ radicals has a positive sensitivity coefficient indicating inhibition of reactivity. This reaction competes for reactive $\mathrm{H}$ atoms at $880 \mathrm{~K}$ where the radical pool is starved by limited production of $\mathrm{OH}$ radicals from allyl+ $\mathrm{HO}_{2}$ reactions due to low $\mathrm{HO}_{2}$ radical 
concentrations, as discussed above. At both temperatures the reactivity is sensitive to reactions forming $\mathrm{HO}_{2}$ radicals: $\mathrm{H}+\mathrm{O}_{2}=\mathrm{HO}_{2}$ reaction, concerted $\mathrm{HO}_{2}$ elimination of CPTO2J and cyclopentyl $+\mathrm{O}_{2}$ reactions leading to cyclopentene $+\mathrm{HO}_{2}$. These $\mathrm{HO}_{2}$ radicals react with allyl radicals and generally lead to $\mathrm{OH}$ formation (except for allyl $+\mathrm{HO}_{2}=\mathrm{C}_{3} \mathrm{H}_{6}+\mathrm{O}_{2}$, an inhibiting reaction due to its chain-termination). Because the reactivity is rate-limited by $\mathrm{HO}_{2}$ formation at $880 \mathrm{~K}$, the allyl $+\mathrm{HO}_{2}$ reactions do not exhibit high sensitivity at $880 \mathrm{~K}$, unlike $850 \mathrm{~K}$ where they show high sensitivity. Other sensitive pathways include the reactions of $\mathrm{O}_{2}$ with $\mathrm{C}_{2} \mathrm{H}_{3}$.

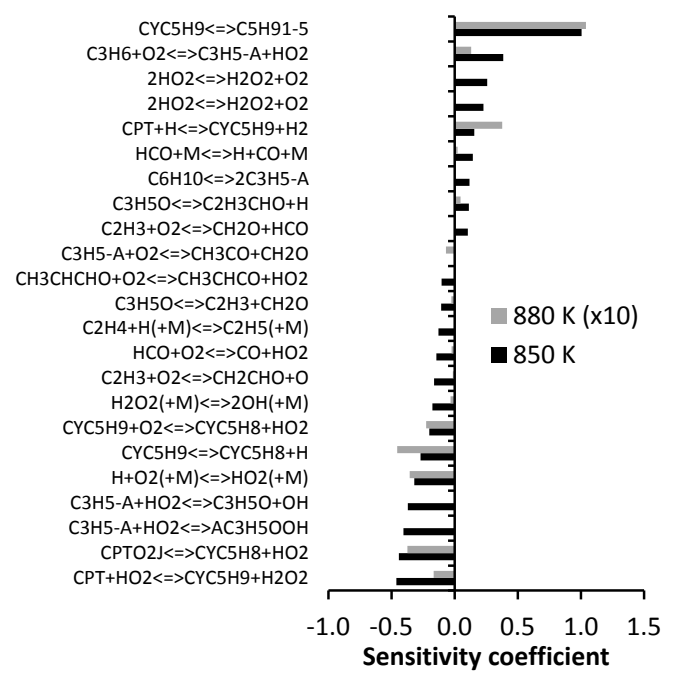

Fig. 7. Sensitivity analysis of cyclopentane fuel concentration at $\varphi=3 / 880 \mathrm{~K}$ and $\varphi=3 / 850 \mathrm{~K}$

Based on the above discussion, we conclude that the suppression of cyclopentane reactivity at rich conditions $(\varphi>2)$ and intermediate temperatures $(850<\mathrm{T}<1000 \mathrm{~K})$ is due to reduction in allyl $+\mathrm{HO}_{2}$ chain branching pathways that lead to the formation of $\mathrm{OH}$ radicals. This behavior becomes evident as equivalence ratio increases beyond $\varphi=2$ because the concentration of $\mathrm{HO}_{2}$ radicals decreases under richer conditions (Fig. S14), which ultimately disfavors chain branching and suppresses reactivity. 
Finally, since allyl radicals are mainly produced from the C-C scission of cyclopentyl radical, this behavior is also sensitive to the $\mathrm{C}-\mathrm{C} / \mathrm{C}-\mathrm{H}$ branching ratio.

\section{Conclusion}

Speciation experiments of cyclopentane combustion were conducted in a jet-stirred reactor at a pressure of $10 \mathrm{~atm}$, temperatures between 740 and $1250 \mathrm{~K}$, and equivalence ratios from 0.5 to 3.0. A detailed kinetic model for cyclopentane oxidation was also developed and compared against the experimental JSR data. To ensure the validity of some important oxidation and pyrolysis reaction rate coefficients, quantum calculations were carried out using ab-intio methods. The simulation results agree with the experiments, and both show an increase in reactivity with increasing temperature at $\varphi=0.5,1.0$ and 1.5. For richer conditions, cyclopentane concentration profiles exhibit inhibition of reactivity between 850 and $1000 \mathrm{~K}$, as evidenced by experimental as well as modeling data. To the best of our knowledge, this behavior has not been observed previously for other fuel molecules, including cyclohexane. Reaction path and sensitivity analyses were conducted to better understand this unique reactivity trend of cyclopentane. The results show that reactivity is highly sensitive to the rates of C-C and $\mathrm{C}-\mathrm{H}$ cyclopentyl scission and that inhibition of reactivity at intermediate to high temperatures may be attributed to the chemistry of allyl radicals. Cyclopentane's distinct reactivity trend presents a knock resistance potential that researchers may find useful in fuel blending or surrogate fuel formulation studies.

\section{Acknowledgements}

This work was funded by King Abdullah University of Science and Technology (KAUST) and Saudi Aramco under the FUELCOM program. It was also supported by competitive research funding from KAUST. JZ was supported by the U.S. Department of Energy, Office of Basic Energy Sciences, Division of Chemical Sciences, Geosciences, and Biosciences. Sandia is a multi-program laboratory 
operated by Sandia Corporation, a Lockheed Martin Company, for the National Nuclear Security Administration, under contract DE-AC04-94AL85000. 


\section{References}

[1] C.S. McEnally and L.D. Pfefferle, Combust. Flame 136 (1-2) (2004) 155-167.

[2] Y. Yang, A.L. Boehman, and J.M. Simmie, Combust. Flame 157 (12) (2010) 2357-2368.

[3] S. Tanaka, F. Ayala, J.C. Keck, and J.B. Heywood, Combust. Flame 132 (2003) 219-239.

[4] API Research Project 45: Knocking Characteristics of Pure Hydrocarbons, ASTM 1958.

[5] Z. Tian, C. Tang, Y. Zhang, J. Zhang, and Z. Huang, Energy Fuels 29 (1) (2015) 428-441.

[6] B.W. Weber, W.J. Pitz, M. Mehl, E.J. Silke, A.C. Davis, and C.-J. Sung, Combust. Flame 161 (2014) 19721983.

[7] S.M. Sarathy, et al., Combust. Flame 169 (2016) 171-193.

[8] R.X. Fernandes, J. Zador, L.E. Jusinski, J.A. Miller, and C.A. Taatjes, Physical chemistry chemical physics : PCCP 11 (9) (2009) 1320-7.

[9] W.J. Pitz, C.V. Naik, T.N. Mhaoldúin, C.K. Westbrook, H.J. Curran, J.P. Orme, and J.M. Simmie, Proc. Combust. Inst. 31 (1) (2007) 267-275.

[10] E.J. Silke, W.J. Pitz, C.K. Westbrook, and M. Ribaucour, J. Phys. Chem. A 111 (2007) 3761-3775.

[11] B. Sirjean, F. Buda, H. Hakka, P.A. Glaude, R. Fournet, V. Warth, F. Battin-Leclerc, and M. Ruiz-Lopez, Proc. Combust. Inst. 31 (1) (2007) 277-284.

[12] S.M. Daley, A.M. Berkowitz, and M.A. Oehlschlaeger, Int. J. Chem. Kin. 40 (10) (2008) 624-634.

[13] S.G. Davis and C.K. Law, Combust. Sci. Tech. 140 (1-6) (1998) 427-449.

[14] V. Simon, Y. Simon, G. Scacchi, and F. Baronnet, Can. J. Chem. 75 (1997) 575-584.

[15] P. Dagaut, M. Cathonnet, J.R. Rouan, R. Foulatier, A. Quilgars, J.C. Boettner, F. Gaillard, and H. James, J. Phys. E 19 (1986) 207-209.

[16] S.M. Burke, W. Metcalfe, O. Herbinet, F. Battin-Leclerc, F.M. Haas, J. Santner, F.L. Dryer, and H.J. Curran, Combust. Flame 161 (11) (2014) 2765-2784.

[17] M.J. Al Rashidi, J. Zádor, M. Mehl, W.J. Pitz, and S.M. Sarathy, Combust. Flame (May 2016)

[18] Y. Yang, A.L. Boehman, and J.M. Simmie, Combust. Flame 157 (12) (2010) 2369-2379.

[19] M.J. Frisch, et al., Wallingford, CT (2009)

[20] H.-J. Werner, P.J. Knowles, G. Knizia, F.R. Manby, and M. Schütz, WIREs Computational Molecular Science 2 (2012) 242-253.

[21] Y. Georgievskii, J.A. Miller, M.P. Burke, and S.J. Klippenstein, J. Phys. Chem. A 117 (2013) 12146-12154.

[22] W. Tsang, J. Phys. Chem. A 110 (2006) 8501-8509.

[23] K. Wang, S.M. Villano, and A.M. Dean, Physical chemistry chemical physics : PCCP 17 (2015) 6255.

[24] I.A. Awan, D.R. Burgess Jr, W. Tsang, and J.A. Manion, Proc. Combust. Inst. 33 (1) (2011) 341-349.

[25] E.R. Ritter and J.W. Bozzelli, Int. J. Chem. Kin. 23 (1991) 767-778.

[26] S.W. Benson, Thermochemical Kinetics; Wiley, New York, 1976.

[27] CHEMKIN-PRO 15131, Reaction Design: San Diego, 2013;

[28] Z. Serinyel, O. Herbinet, O. Frottier, P. Dirrenberger, V. Warth, P.A. Glaude, and F. Battin-Leclerc, Combust. Flame 160 (2013) 2319-2332.

[29] W. Tsang, Int. J. Chem. Kin. 10 (1978) 599-617.

[30] S.M. Sarathy, et al., Combust. Flame 158 (12) (2011) 2338-2357.

[31] P.T. Lynch, C.J. Annesley, C.J. Aul, X. Yang, and R.S. Tranter, J. Phys. Chem. A 117 (2013) 4750-4761.

[32] C.F. Goldsmith, W.H. Green, and S.J. Klippenstein, J. Phys. Chem. A 116 (2012) 3325-3346. 


\section{List of Tables and Figures}

Fig. 1. Experimental concentration profiles of cyclopentane with increasing JSR temperature and for different equivalence ratios ( $\mathrm{P}=10 \mathrm{~atm}, 0.1 \%$ fuel $/ \mathrm{O}_{2} / \mathrm{N}_{2}$ mixtures).

Fig. 2. Experimental (symbols) and modeled (lines) concentration profiles of detected species at $\mathrm{P}=10$ atm and $\varphi=0.5$

Fig. 3. Experimental (symbols) and modeled (lines) concentration profiles of detected species at $\mathrm{P}=10$ atm and $\varphi=1.0$

Fig. 4. Experimental (symbols) and modeled (lines) concentration profiles of detected species at $\mathrm{P}=10$ atm and $\varphi=3.0$

Fig. 5. Experimental and simulated concentration profiles of cyclopentane at $P=10$ atm and $\varphi=3.0$ using rate coefficients for $\mathrm{C}-\mathrm{C}$ and $\mathrm{C}-\mathrm{H}$ scission of cyclopentyl from different references [11, 22-24]. "Comp" refers to the use of rate parameters determined computationally in this study for $\mathrm{C}-\mathrm{C}$ and $\mathrm{C}-\mathrm{H}$ scission.

Fig. 6. Reaction path analysis of cyclopentane decomposition for $\varphi=3 / 850 \mathrm{~K}$ (plain font), $\varphi=3 / 880 \mathrm{~K}$ (italic font), and $\varphi=1 / 880 \mathrm{~K}$ (bold font)

Fig. 7. Sensitivity analysis of cyclopentane fuel concentration at $\varphi=3 / 880 \mathrm{~K}$ and $\varphi=3 / 850 \mathrm{~K}$

Table 1. C-C/C-H scission branching ratios of the cyclopentyl radical at 500, 1000 and $1500 \mathrm{~K}$ based on literature high pressure limit rate coefficients and this study 